\title{
Studi Komparatif antara Ragam Hias Batik Tradisional Bakaran dengan Ragam Hias Batik Keraton Surakarta
}

\author{
Ulfa Septiana, Yan Yan Sunarya \& Achmad Haldani \\ Faculty of Visual Art and Design, Institut Teknologi Bandung \\ Jalan Ganesa No. 10, Bandung 40132, Indonesia \\ Email: ulfa.hadi@yahoo.com
}

\begin{abstract}
Abstrak Batik Bakaran merupakan kerajinan batik yang berkembang di Desa Bakaran, yaitu salah satu desa di Kabupaten Pati yang terketak di pesisir pantai utara Pulau Jawa. Ragam hias tradisional dari batik Bakaran tidak memperlihatkan pengaruh asing seperti batik pesisiran pada umumnya, tetapi mirip dengan ragam hias dari daerah pedalaman Jawa, khususnya Keraton Surakarta. Penelitian ini bertujuan untuk memaparkan unsur-unsur estetik ragam hias dan ciri khas dari batik tradisional Bakaran dan batik Keraton Surakarta, serta mengidentifikasi penyebab adanya kemiripan antara ragam hias kedua jenis batik tersebut. Penelitian ini menggunakan metode kualitatif deskriptif, dengan pendekatan komparatif dan estetik. Berdasarkan kajian dan analisa dari data pustaka maupun lapangan, didapatkan kesimpulan bahwa ragam hias batik tradisional Bakaran dan batik Keraton Surakarta memiliki kesamaan pada unsurunsur estetiknya, yaitu motif utama dari ragam hias kedua jenis batik tersebut yang dibandingkan. Kemiripan yang terjadi pada kedua jenis batik tersebut didominasi oleh faktor hubungan perdagangan antar daerah pembatikan di masa lalu. Terdapat pula perbedaan yang menjadi ciri khas kedua daerah tersebut, yaitu ukuran dan bentuk motif pada batik tradisional Bakaran umumnya lebih besar dan sederhana jika dibandingkan dengan batik Keraton Surakarta.
\end{abstract}

Kata kunci: estetik; ragam hias; batik tradisional Bakaran; batik Keraton Surakarta.

\begin{abstract}
Bakaran batik is a batik that is developed in Bakaran Village, Pati Regency at the North Coast of Java. Traditional ornaments in Bakaran batik show no influence from foreign cultures in general coastal batik, but are similar to the ornamentation of the Keraton Surakarta batik. This study aims to describe the elements of ornamentation and aesthetic characteristics of traditional Bakaran and Keraton Surakarta batik, and to identify the cause of the similarity between them. The conclusion is the ornamentation of Bakaran traditional batik and Keraton Surakarta one, have similarities to the main motive of the batik ornaments, that occur between Bakaran traditional batik and Keraton Surakarta one were caused by the trade relations between regions of both batiks in the past. There are also differences that characterize these batiks, the size and shape of the batik motifs on the traditional batik.
\end{abstract}

Keywords: aesthetic; Keraton Surakarta batik; ornament; traditional Bakaran batik.

Received August $31^{\text {st }} 2012$, Revised September $26^{\text {th }}, 2013$, Accepted November $30^{\text {th }}, 2013$.

Copyright (C) 2013 Published by LPPM ITB, ISSN: 1978-3078, DOI: 10.5614/itbj.vad.2013.5.1.2 


\section{$1 \quad$ Pendahuluan}

Juwana adalah satu di antara daerah pesisir pantai utara pulau Jawa, di Kabupaten Pati, yang memiliki pusat kerajinan batik Bakaran. Nama batik ini diambil dari nama desa tempat pusat kerajinan batik tersebut berasal, yaitu Desa Bakaran. Sebutan "batik Bakaran" masih asing di telinga masyarakat saat ini, karena telah lama menghilang di pasaran. Menurut Kerlogue [1], hal tersebut disebabkan oleh penurunan produksi dan surutnya perdagangan pada tahun 1930-an akibat ketidakstabilan suasana politik di dunia, yang turut berimbas pada Hindia Belanda, serta mulai pecahnya perang Asia Pasifik. Namun jauh setelah itu, pada tahun 2006 terjadi tren batik di Indonesia, sehingga batik Bakaran dapat terangkat kembali dan diperkenalkan secara luas sebagai warisan leluhur desa Bakaran. Tetapi desain batik yang berkembang setelah tahun 1998 adalah desain batik kontemporer yang tidak lagi terikat pada tradisi karena mengikuti selera pasar, yang menyebabkan perhatian masyarakat pada batik tradisional Bakaran menurun, dan produksinya hanya dilakukan sesuai pesanan.

Sejauh ini ragam hias batik tradisional yang ada di Bakaran yang telah teridentifikasi terdiri atas 22 ragam hias, antara lain gandrung, blebak urang, puspo baskoro, limaran, blebak duri, nogo rojo, gringsing, merak ngigel, magel ati, dengan warna dasar soga dan biru tua serta tapak batikan putih terang [2]. Disebut pula pada penelitian terdahulu penulis [3], bahwa beberapa ragam hias batik tradisional Bakaran memiliki kemiripan pada nama dan bentuk motif dengan batik Keraton. Ragam hias tersebut di antaranya padas gempal dengan sekar jagad, dan kawung tunjung dengan kawung picis. Hal ini membedakan batik Bakaran dengan kebanyakan batik dari daerah pesisir lain, yang biasanya mendapatkan pengaruh bangsa asing seperti Cina, India, Arab atau Belanda.

Objek penelitian yang diperbandingkan di sini adalah Batik Keraton, batik yang berkembang di daerah kerajaan di Pulau Jawa, seperti Keraton Kasunanan Surakarta Hadiningrat dan Keraton Kasultanan Yogyakarta Hadiningrat. Kedua Kerajaan ini merupakan pecahan dari kerajaan Mataram Islam. Batik Keraton dipercaya mewarisi ragam hias batik dari masa Kerajaan Majapahit, yang telah diwarisi oleh Kerajaan Demak, Kerajaan Pajang dan Kerajaan Mataram Islam yang ada sebelum Kasunan Surakarta Hadiningrat dan Kasultanan Yogyakarta Hadiningrat berdiri. Berbeda dengan batik pesisir, ragam hias batik Keraton mayoritas berpola simetris, motif besar, mengangkat tema kehidupan masyarakat darat seperti hutan, hasil bumi, dan agraria serta simbol-simbol kerajaan. Pemilihan warnanya didasarkan pada nuansa alam, seperti coklat sogan yang menggambarkan kebersahajaan dan membumi. Hal tersebut selaras dengan kehidupan sosial, budaya, lingkungan Surakarta dan Yogyakarta sebagai lingkup Keraton dengan karakter halus dan pelan [4]. 
Karakteristik batik Keraton Yogyakarta mewarisi sepenuhnya ragam hias batik Keraton Mataram Islam, sedangkan batik Keraton Surakarta, ragam hiasnya merupakan gubahan ulang yang mengikuti pakem-pakem dari batik Keraton Mataram Islam. Gubahan ulang batik Mataram Islam oleh Keraton Surakarta tersebut menjadikan ragam hiasnya lebih dinamis serta berukuran lebih kecil daripada ragam hias batik Keraton Yogyakarta. Demikian pula dalam hal warna, batik Keraton Surakarta dominan sogan kekuningan, sedangkan batik Keraton Yogyakarta berwarna sogan tua dan putih. Selain itu, makna yang terkandung di dalam batik Keraton Surakarta mengikuti filosofi yang dibuat oleh Raja-Raja Keraton Surakarta sejak Paku Buwono III.

Beberapa pakar batik, di antaranya Toetti T. Soerjanto, menyatakan bahwa batik tradisional Bakaran memperlihatkan kemiripan dengan batik Keraton Surakarta. Kemiripan tersebut dimungkinkan terjadi oleh adanya hubungan politis antara kedua daerah tersebut pada masa lalu, yang menyebarkan batik Keraton Surakarta ke daerah Pati [5]. Menurut pendapat Bukhari, kemiripan batik tradisional Bakaran dengan batik Keraton Surakarta kemungkinan terjadi karena ragam hias batik kedua daerah tersebut merupakan warisan dari Kerajaan Majapahit. Hal ini dijelaskan oleh legenda leluhur desa Bakaran, yaitu Nyai Ageng Danowati yang berasal dari Kerajaan Majapahit dan masih dipercayai penduduk sekitar sampai kini. Selain itu juga dapat disebabkan oleh adanya hubungan antara daerah Pati dengan Surakarta di masa lampau, baik dalam bidang perdagangan maupun politik. Perdagangan dan pengaruh politik atau kekuasaan dapat mempengaruhi produk kebudayaan daerah lainnya, seperti yang terjadi pada ragam hias batik tradisional Bakaran yang kemungkinan mendapatkan pengaruh dari Keraton Surakarta (Bukhari, pengusaha batik Bakaran, wawancara, 20 Oktober 2008).

Berdasar pertelaan itu, maka penelitian ini bertujuan memaparkan unsur-unsur estetik ragam hias dan ciri khas dari batik tradisional Bakaran dan batik Keraton Surakarta, serta mengidentifikasi penyebab adanya kemiripan antara ragam hias kedua jenis batik ini. Kajian perbandingan visual, warna, dan komposisi ragam hias antara kedua jenis batik tersebut menarik untuk dikaji, karena batik tradisional Bakaran tidak seperti batik pesisir yang umumnya lebih bebas dari pengaruh batik Keraton Surakarta.

\section{Metodologi Penelitian}

\subsection{Objek dan Lokasi Penelitian}

Objek yang diteliti adalah batik tradisional Bakaran dan batik Keraton Surakarta. Lokasi penelitian dilakukan di Desa Bakaran, Kabupaten Pati dan Kota Surakarta. Pengambilan sampel batik tradisional Bakaran dilakukan di 
perusahaan batik Tjokro, sedangkan sampel batik Keraton Surakarta diambil di Museum Batik Kuno Danar Hadi, karena kedua lokasi tersebut dianggap memiliki koleksi batik tradisional yang lengkap.

\subsection{Metode Penelitian}

a. Pendekatan komparatif, untuk membandingkan ragam hias batik tradisional Bakaran dengan batik Keraton Surakarta beserta kaitannya yang menyebabkan keduanya memiliki kemiripan.

b. Pendekatan estetik, untuk mengidentifikasi ragam hias batik tradisional Bakaran dan batik Keraton Surakarta dengan melihat wujud visual mulai dari bentuk, warna, dan komposisi ragam hias. Pada pendekatan ini digunakan teori ragam hias batik dari Sewan Susanto [6] dan teori estetik mengenai wujud karya seni atau ragam hias dari A.A.M Djelantik [7] untuk mengkaji unsur-unsur estetik kedua objek yang memiliki kemiripan. Selain itu pula teori faktor pembentuk ragam hias dari Nian S. Djoemena [8] untuk membandingkan kedua objek penelitian berdasarkan faktor pembentuknya agar dapat diketahui penyebab kemiripannya.

\section{Hasil dan Pembahasan}

\subsection{Perbandingan Estetik antara Ragam Hias Batik Tradisonal Bakaran dengan Ragam Hias Batik Keraton Surakarta}

Berdasarkan kajian pustaka maupun lapangan, didapatkan kemiripan pada unsur-unsur estetiknya. Hal ini berdasar amatan terhadap batik tradisional Bakaran dan batik Keraton Surakarta. Berikut ini adalah perbandingan ragam hias batik tradisional Bakaran dan batik Keraton Surakarta yang memiliki kemiripan pada unsur-unsur estetiknya.

Ragam hias batik tradisional bakaran di Batik Tjokro yang teridentifikasi memiliki kemiripan dengan batik Keraton Surakarta di Museum Batik Kuno Danar Hadi antara lain (1) ragam hias sido rukun dengan ragam hias sido rukun, (2) ragam hias truntum dengan ragam hias truntum, (3) ragam hias kawung tunjung dengan ragam hias kawung picis, (4) ragam hias padas gempal dengan ragam hias sekar jagad, (5) ragam hias liris dengan ragam hias udan liris, dan (6) ragam hias blebak kopik dengan ragam hias semen rama (lihat Tabel 1). 
Tabel 1 Perbandingan Ragam Hias Batik Tradisional Bakaran dengan Batik Keraton Surakarta.

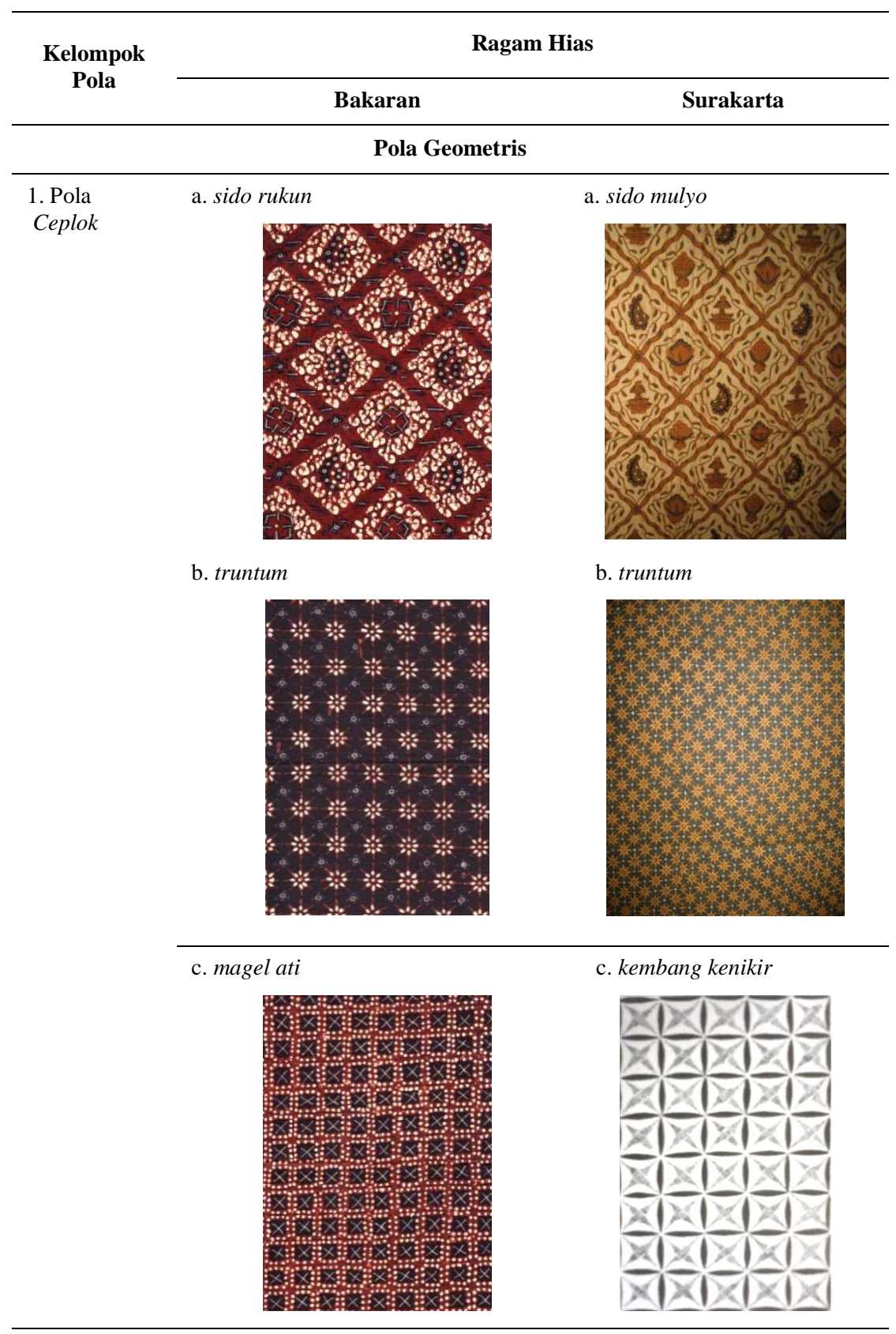




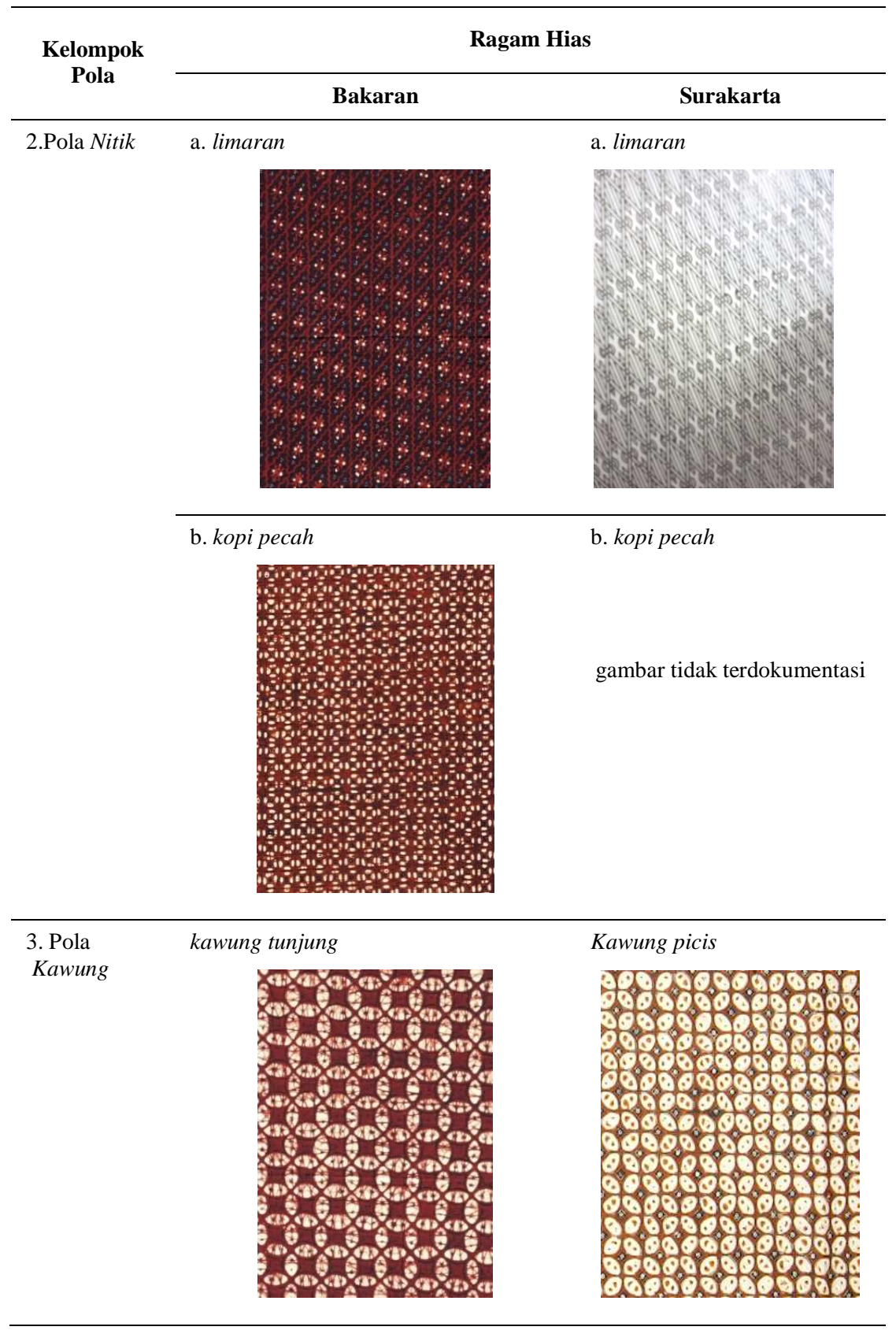




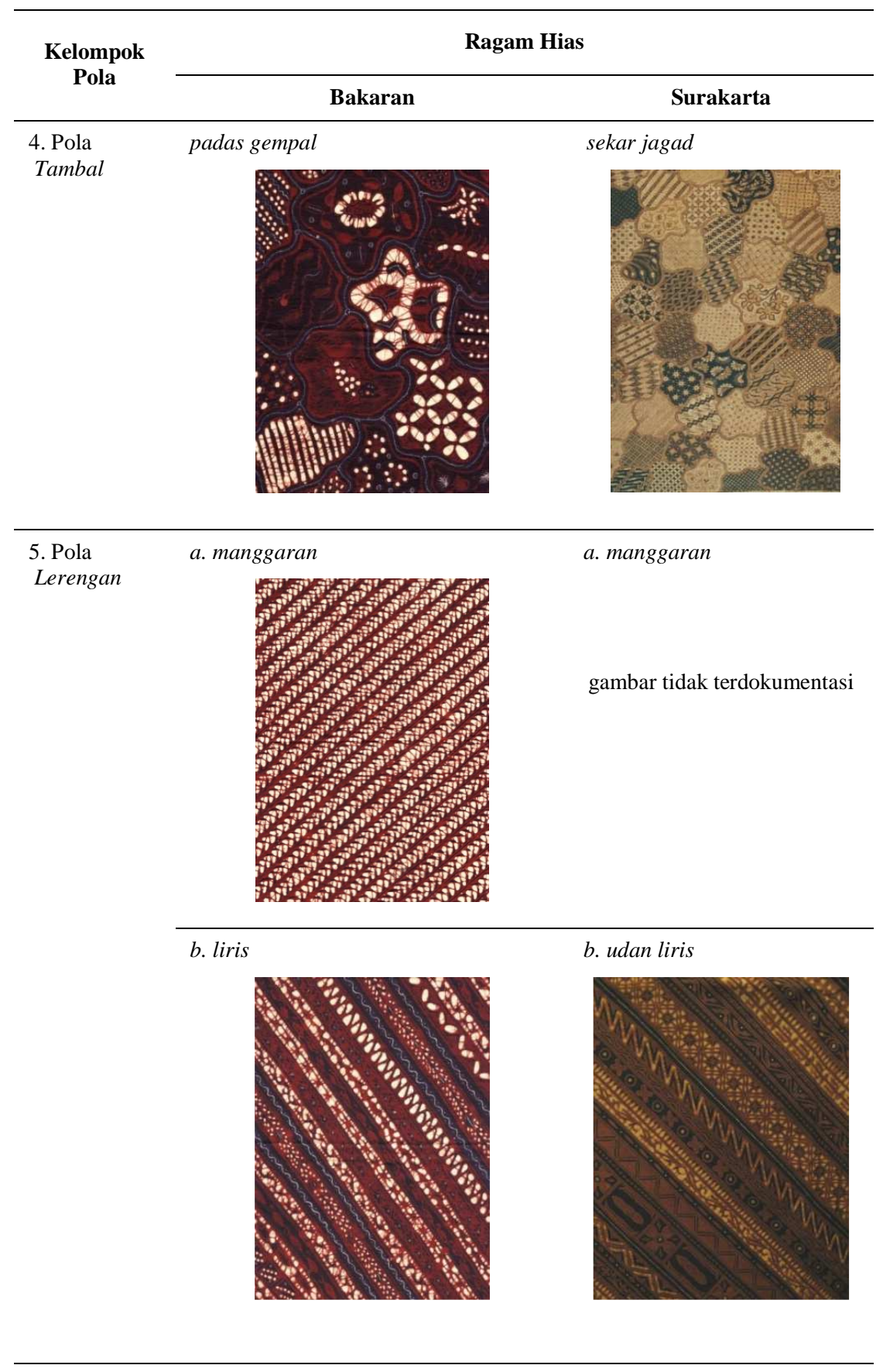




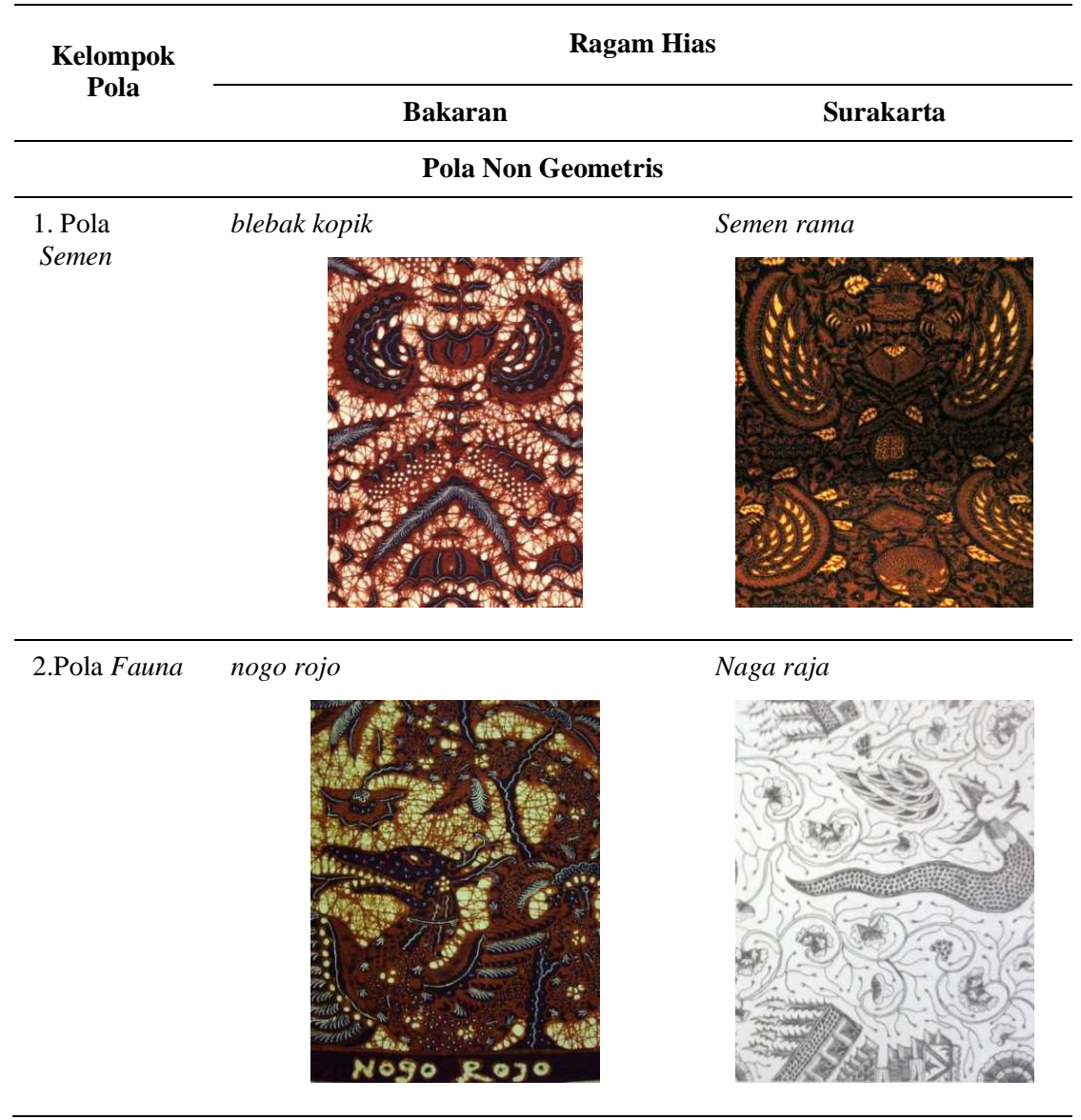

\subsubsection{Kemiripan antara Batik Tradisional Bakaran dengan Batik Keraton Surakarta}

Kemiripan antara batik tradisional Bakaran dengan batik keraton Surakarta terlihat pada unsur-unsur pembentuk ragam hias atau motifnya seperti berikut:

1. Ragam hias sido rukun dari Bakaran dan sido mulyo dari Surakarta, memiliki kerangka motif utama berupa bidang jajar genjang dan motif lar. Tetapi, bentuk lar pada ragam hias sido rukun lebih lebar dari pada lar yang terdapat pada ragam hias sido mulyo.

2. Ragam hias truntum dari Bakaran dengan truntum dari Surakarta, memiliki motif utama berbentuk bintang menyerupai 8 buah kelopak bunga yang disatukan oleh suatu titik di bagian tengahnya. Motif bintang pada kedua ragam hias ini memiliki ukuran berbeda, pada truntum Bakaran diameter 
motif mencapai $\pm 3 \mathrm{~cm}$, sedangkan pada truntum Surakarta diameter motif lebih kecil, yaitu $\pm 2 \mathrm{~cm}$. Jika dibandingkan perbedaan ukuran keduanya tampak tidak terlalu signifikan, tetapi bagian pangkal kelopak bintang pada ragam hias truntum dari Bakaran terdapat isen cecek berwarna putih, sehingga warna motif menjadi kontras dengan latarnya dan tampak lebih menonjol dan besar. Adapun motif bintang pada ragam hias truntum dari Surakarta tidak memiliki isen cecek berwarna putih, sehingga tidak terlihat adanya kekontrasan dengan warna latarnya.

3. Ragam hias kawung tunjung dari Bakaran dan kawung picis dari Surakarta, memiliki motif utama terdiri atas susunan 4 buah biji kawung, tetapi setiap sudut terluar pada motif utama ragam hias kawung tunjung Bakaran membentuk bidang jajar genjang, sedangkan ragam hias kawung picis Surakarta membentuk bidang persegi.

4. Ragam hias padas gempal dari Bakaran dan sekar jagad dari Surakarta, memiliki kerangka motif utama berbentuk seperti gumpalan batu atau mahkota bunga dari garis $\mathrm{S}$ dengan ukuran tidak beraturan. Tetapi pada bagian dalam kerangka motif utama ragam hias padas gempal dari Bakaran terdapat rangkaian isen-isen cecek dan isen mata deruk, sedangkan pada kerangka motif utama ragam hias sekar jagad dari Surakarta tidak terdapat isen-isen.

5. Ragam hias liris dari Bakaran dan udan liris dari Surakarta, memiliki motif kawungan dan susunan motif ke arah diagonal. Tetapi warna pada motif kawungan pada ragam hias liris Bakaran berwarna putih, sehingga terkesan lebih besar dan menonjol jika dibandingkan dengan motif kawungan pada ragam hias udan liris Surakarta yang berwarna putih dan coklat sogan yang tidak merata.

6. Ragam hias blebak kopik dari Bakaran dan semen rama dari Surakarta, memiliki motif lar, meru, dampar, pohon hayat dan tumbuhan. Tetapi bentuk yang terdapat pada ragam hias blebak kopik dari Bakaran lebih sederhana dan disesuaikan dengan kondisi alam setempat. Hal ini terlihat pada motif tumbuhan druju yang menjadi motif khas pada batik Bakaran.

Selain unsur pembentuk ragam hias, kemiripan antara batik tradisional Bakaran dengan batik keraton Surakarta dapat dilihat oleh pola pengulangan motif dan warnanya. Kesamaan pola pengulangan motif terlihat pada ragam hias sido rukun dari Bakaran dan sido mulyo dari Surakarta yang menggunakan sistem tubruk miring. Demikian pula pada ragam hias truntum Bakaran, truntum Surakarta, kawung tunjung Bakaran dan kawung picis Surakarta pola pengulangan motif menggunakan sistem tubruk. Adapun pola pengulangan motif pada ragam hias liris dari Bakaran dan udan liris dari Surakarta menggunakan sistem miring. 
Kemiripan lain terlihat pada nuansa warna, kedua jenis batik tersebut didominasi warna coklat sogan, hitam dan putih. Namun demikian jika kedua jenis batik tersebut dilihat berdasarkan warna pantone dan dibandingkan terlihat ada perbedaan. Warna putih pada batik tradisional Bakaran lebih terang daripada batik Keraton Surakarta.

\subsubsection{Ciri Khas Batik Tradisional Bakaran dan Batik Keraton Surakarta}

Secara umum, ciri khas pada batik tradisional Bakaran dan batik Keraton Surakarta terlihat pada perbedaan di antara keduanya. Perbedaan tersebut terlihat pada unsur-unsur wujud ragam hiasnya, yaitu titik, garis, bidang dan warnanya, dapat dilihat pada Tabel 2 sebagai berikut:

Tabel 2 Perbandingan unsur-unsur wujud Ragam Hias Batik Tradisional Bakaran dengan Batik Keraton Surakarta.

\begin{tabular}{|c|c|c|}
\hline $\begin{array}{c}\text { Unsur-unsur } \\
\text { wujud ragam hias }\end{array}$ & Batik Tradisional Bakaran & Batik Keraton Surakarta \\
\hline Titik & $\begin{array}{l}\text { Digunakan sebagai isen-isen } \\
\text { cecek maupun pendukung isen- } \\
\text { isen lainnya dengan ukuran kecil } \\
\text { dan bentuk setiap cecek berbeda, } \\
\text { serta jarak antar cecek tidak } \\
\text { konsisten. }\end{array}$ & $\begin{array}{l}\text { Digunakan juga sebagai isen- } \\
\text { isen cecek maupun pendukung } \\
\text { isen-isen lainnya, dengan } \\
\text { ukuran titik yang sama dan } \\
\text { kecil, tetapi lebih besar dari } \\
\text { pada unsur titik pada batik } \\
\text { tradisional Bakaran, serta } \\
\text { bentuk setiap titiknya sama dan } \\
\text { jarak antar titik konsisten. }\end{array}$ \\
\hline Garis & $\begin{array}{l}\text { Digunakan sebagai pembentuk } \\
\text { motif, isen-isen sawut, maupun } \\
\text { pendukung isen-isen lainnya } \\
\text { dengan tebal-tipis yang tampak } \\
\text { tidak konsisten. }\end{array}$ & $\begin{array}{l}\text { Kegunaan unsur ini masih } \\
\text { sama dengan unsur garis pada } \\
\text { batik tradisional Bakaran, } \\
\text { tetapi goresan garis tampak } \\
\text { konsisten tebal tipisnya, serta } \\
\text { tarikan garisnya lebih luwes. }\end{array}$ \\
\hline Bidang & $\begin{array}{l}\text { Unsur ini membentuk unsur-unsur } \\
\text { ragam hias atau motif pada ragam } \\
\text { hias, dan umumnya karakteristik } \\
\text { detil dari bentuk motif lebih } \\
\text { sederhana jika dibandingkan } \\
\text { dengan batik Keraton Surakarta. }\end{array}$ & $\begin{array}{l}\text { Detil unsur motif lebih } \\
\text { kompleks dan ragamnya } \\
\text { variatif dari pada motif yang } \\
\text { terdapat pada ragam hias batik } \\
\text { tradisional Bakaran. }\end{array}$ \\
\hline Warna & $\begin{array}{l}\text { Warna putih pada batik tradisional } \\
\text { Bakaran lebih putih, dan warna } \\
\text { coklat sogan dan hitam lebih tua } \\
\text { dibandingkan dengan batik } \\
\text { Keraton Surakarta, sehingga }\end{array}$ & $\begin{array}{l}\text { Warna putih lebih tua, dan } \\
\text { warna coklat sogan dan hitam } \\
\text { lebih muda dibandingkan } \\
\text { dengan batik tradisional } \\
\text { Bakaran. }\end{array}$ \\
\hline
\end{tabular}




\begin{tabular}{ccc}
\hline $\begin{array}{c}\text { Unsur-unsur } \\
\text { wujud ragam hias }\end{array}$ & Batik Tradisional Bakaran & Batik Keraton Surakarta \\
\hline & $\begin{array}{l}\text { warna putih terlihat menonjol } \\
\text { karena warna putih dengan coklat } \\
\text { sogan dan hitamnya kontras. }\end{array}$ & \\
Pantone 587 CS & Pantone 450 CS \\
Pantone Black 2 CS & Pantone 449 CS \\
Pantone 5605 CS & Pantone 296 CS \\
\hline
\end{tabular}

Pada penjelasan unsur bidang disebutkan bahwa bentuk motif pada batik tradisional Bakaran lebih sederhana jika dibandingkan dengan batik Keraton Surakarta. Perbandingan tersebut dapat dilihat sebagai berikut ini:

a. Motif lar pada ragam hias sido mulyo Surakarta dan sido rukun Bakaran (Gambar1).

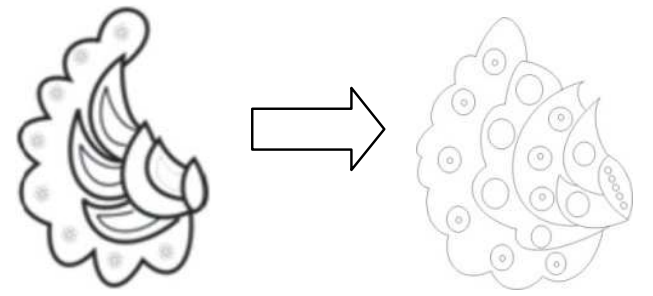

Gambar 1 Penyederhanaan bentuk dan detil pada motif lar.

b. Motif kawung pada ragam hias sekar jagad Surakarta dan padas gempal Bakaran (Gambar 2)

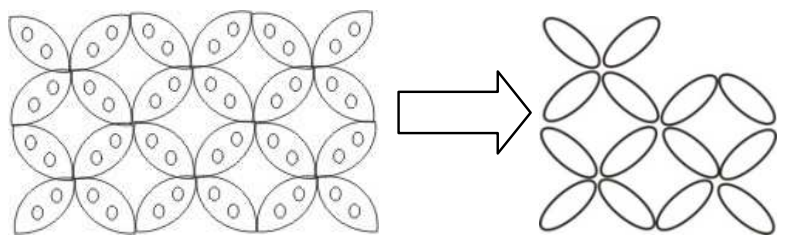

Gambar 2 Penyederhanaan bentuk dan detil pada motif kawung. 
c. Motif lar pada ragam hias semen rama Surakarta dan blebak kopik Bakaran (Gambar 3)

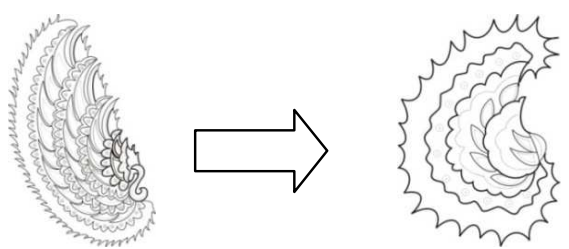

Gambar 3 Penyederhanaan bentuk dan detil pada motif lar.

d. Motif pohon hayat pada ragam hias semen rama Surakarta dan blebak kopik Bakaran (Gambar 4)

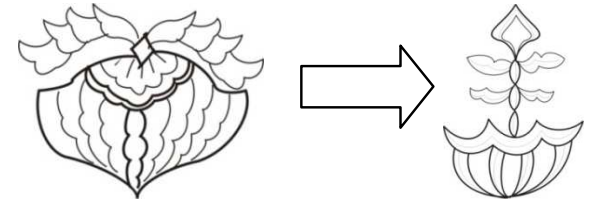

Gambar 4 Penyederhanaan bentuk dan detil pada motif pohon hayat.

e. Motif dampar pada ragam hias semen rama Surakarta dan blebak kopik Bakaran (Gambar 5)

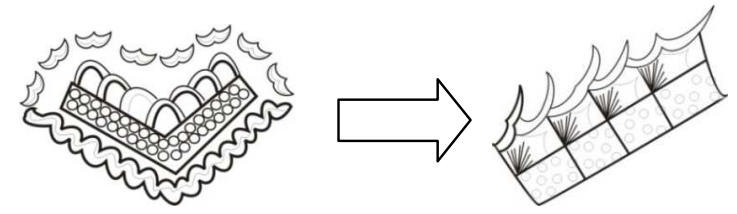

Gambar 5 Penyederhanaan bentuk dan detil pada motif dampar.

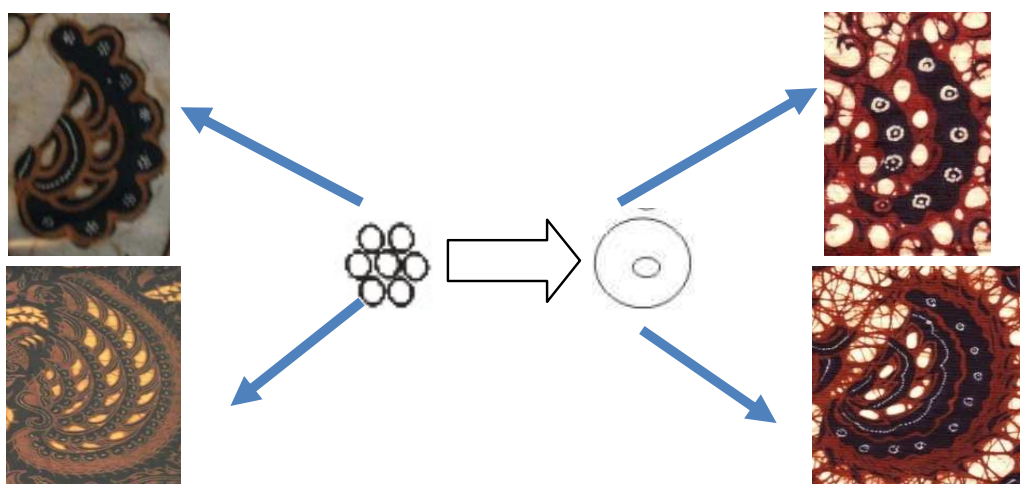

Gambar 6 Penyederhanaan pada isen-isen. 
Penyederhanaan bentuk pada unsur ragam hias terjadi juga pada isen-isen (lihat Gambar 6). Hal ini terlihat pada isen cecek pitu di bagian sayap terluar motif lar pada ragam hias sido mulyo dan semen rama dari Surakarta, menjadi isen mata deruk dengan isen cecek di bagian dalamnya pada motif lar ragam hias sido rukun dan blebak kopik dari Bakaran.

\subsection{Penyebab Kemiripan Ragam Hias antara Batik Tradisional Bakaran dengan Batik Keraton Surakarta}

Perbandingan faktor-faktor pembentuk ragam hias kedua jenis batik tersebut menunjukkan bahwa letak geografis masing-masing daerah tidak mempengaruhi ragam hias batiknya. Karena pengaruh asing pada batik tradisional Bakaran hanya terlihat pada ragam hias burung loek chan, sedangkan pengaruh asing pada batik di Surakarta terlihat pada batik yang berkembang di luar Keraton saja, dan tidak mempengaruhi batik Keraton Surakarta.

Faktor yang menunjukkan kemiripan pada daerah Pati dengan Surakarta adalah kepercayaan dan adat istiadat serta keadaan alamnya. Kedua daerah ini memiliki penduduk yang menganut kepercayaan kejawen dan masih melakukan ritual kejawen tersebut sampai saat ini, seperti kirab pusaka. Karena kesamaan dalam kepercayaan kejawen serta nasionalisme masyarakat kedua daerah ini setempat terhadap sejarah masa lalu, di kedua daerah ini terdapat ragam hias sido rukun dan truntum (dari Bakaran) yang memperlihatkan kemiripan visual dengan sido mulyo dan truntum (dari Keraton Surakarta).

Kesamaan kondisi alam kedua daerah ini adalah berada pada daerah tropis dan merupakan daerah rawa pada masa lalu. Walaupun demikian, pada batik Keraton Surakarta tidak banyak yang menggambarkan keadaan alamnya, kecuali ragam hias manggaran yang menggambarkan bunga dari pohon kelapa, sebagai simbol kesuburan. Ragam hias manggaran juga terdapat di Desa Bakaran, tetapi tidak sebagai simbol apapun. Persamaan ragam hias ini terjadi karena di kedua daerah ini pohon kelapa dapat tumbuh subur.

Faktor hubungan antara kedua daerah tersebut, merupakan faktor dominan menjadi penyebab adanya kemiripan visual antara ragam hias batik tradisional Bakaran dengan batik Keraton Surakarta. Hubungan tersebut dapat terjadi karena hubungan politik maupun perdagangan. Hubungan politik kedua daerah ini terputus sejak adanya perjanjian dengan Belanda dalam hal kekuasaan. Sehingga kemiripan ragam hias kedua daerah ini disebabkan oleh hubungan politik dapat terjadi pada masa Kerajaan Mataram Islam, sebelum digantikan oleh Kasunanan Surakarta Hadiningrat. Hubungan kedua daerah ini lebih dimungkinkan oleh adanya perdagangan antara kedua daerah ini. Kaum sudagar dari Surakarta diketahui mengadakan kontak dagang dengan daerah pesisir yang 
tidak termasuk dalam kekuasaan Kasunanan Surakarta, seperti Lasem, Kudus, Semarang dan Pekalongan. Sehingga ada kemungkinan melakukan kontak dagang dengan daerah Pati yang terletak di antara Kudus dan Lasem (lihat Tabel 1 dan 2), bahwa proses medel pada batik tradisional Bakaran dilakukan di daerah Surakarta, karena ada pantangan melakukan proses ini di Desa Bakaran.

Menurut Koentjaraningrat [9], kebudayaan pesisir dinyatakan tidak terlalu terikat pada kebudayaan Keraton di daerah pedalaman, serta batik tradisional Bakaran dinyatakan berasal dari Keraton Majapahit oleh masyarakat yang mengembangkannya. Walaupun demikian, Toetti T. Soerjanto (kurator Museum Batik Kuno Danar Hadi, wawancara, 21 April 2011) berpendapat bahwa ragam hias batik tradisional Bakaran berasal dari Keraton Surakarta. Pernyataan tersebut didasarkan oleh fakta bahwa ada beberapa kerajinan batik daerah di pesisir seperti Batang dan Tegal yang memiliki ragam hias batik tradisional mirip dengan batik Keraton Yogyakarta. Selain dua daerah tersebut ada pun daerah Pacitan, Ponorogo dan Tulungagung yang memiliki batik tradisional yang mirip dengan Keraton Surakarta. Hal ini terjadi karena pada masa lalu, para pejabat yang berkuasa di daerah kekuasaan Kasultanan Yogyakarta Hadiningrat Hadiningrat maupun Kasunanan Surakarta Hadiningrat diharuskan menghadap ke Keraton Kasultanan Yogyakarta Hadiningrat dan Keraton Kasunanan Surakarta Hadiningrat untuk melaksanakan upacara adat semacam apel setiap periode tertentu. Selain melaksanakan apel, para pejabat tersebut diberi misi oleh Keraton untuk menyebarkan unsur-unsur budaya yang berpusat ke Keraton di daerahnya masing-masing, salah satunya adalah batik.

Batik yang berasal dari Keraton dikembangkan oleh daerah-daerah kekuasaan Kasultanan maupun Kasunanan dengan digubah ulang sesuai kondisi dan selera masyarakat setempat. Hal ini dilakukan agar batik dapat dipakai oleh masyarakat umum, karena batik Keraton tidak boleh dipakai secara sembarangan oleh rakyat. Penggubahan batik Keraton biasanya terjadi pada batik sudagaran serta batik petani, seperti batik di Desa Bakaran

\section{Kesimpulan}

Ragam hias batik tradisional Bakaran dan batik Keraton Surakarta memiliki kesamaan pada unsur-unsur estetiknya, yaitu motif utama dari ragam hias kedua jenis batik tersebut yang dibandingkan. Kemiripan yang terjadi pada kedua jenis batik tersebut didominasi oleh faktor hubungan perdagangan antardaerah pembatikan di masa lalu. Terdapat pula perbedaan yang menjadi ciri khas kedua daerah tersebut, yaitu ukuran dan bentuk motif pada batik tradisional Bakaran umumnya lebih besar dan sederhana jika dibandingkan dengan batik Keraton Surakarta. 


\section{Referensi}

[1] Kerlogue, F. 2004. The Book of Batik. Singapore: Archipelago Press.

[2] Supriyadi, S. 2008. Pengembangan Model Revitalisasi Industri Batik Bakaran Sebagai Upaya Meningkatkan Ekonomi Masyarakat Sekitarnya Melalui Program Pariwisata Budaya (Studi Kasus Seni Batik Tradisional di Kabupaten Pati), dalam Laporan Penelitian Tahun I Hibah Bersaing Perguruan Tinggi, Anggaran 2009. Surakarta: LPPM UNS.

[3] Septiana, U. 2009. Kajian Ragam Hias Batik Tradisi Bakaran, Skripsi Universitas Sebelas Maret, Surakarta.

[4] Djoemena, N. 1986. Ungkapan Sehelai Batik, Jakarta: Djambatan.

[5] Soerjanto, T.T. 21 April 2011. wawancara, kurator Museum Batik Kuno Danar Hadi.

[6] Susanto, S. 1980. Seni Kerajinan Batik Indonesia. Yogyakarta: Departemen Perindustrian RI.

[7] Djelantik, A.A.M. 1999. Estetika Sebuah Pengatar, Bandung: MSPI.

[8] Djoemena, N. 1986. Ungkapan Sehelai Batik, Jakarta: Djambatan.

[9] Koentjaraningrat. 1984. Kebudayaan Jawa, Jakarta: Balai Pustaka. 